\title{
4. \\ IZMEĐU RATNOG BEOGRADA I „RADNIH” LOGORA NEMAČKE: \\ BRANKO LAZAREVIĆ I STANISLAV VINAVER
}

\section{Sava Damjanov}

UDK: 821.163.41-94"194“"

Prethodno priopćenje

Sažetak: Dva značajna aktera srpskog modernizma, Branko Lazarević (1883-1968) i Stanislav Vinaver (1891-1955), našli su se tokom Drugog svetskog rata u različitim okolnostima lične neslobode. Dok je Lazarević kao ugledni diplomata poražene države uspeo da se domogne Beograda i u njemu provede godine okupacije, Vinaver je čitav rat proveo u logorima Trećega rajha. Dnevnik jednoga nikoga Branka Lazarevića objavljen je tek 2008 (posthumno), a Godine poniženja i borbe Stanislava Vinavera 1945 (u tek oslobođenoj Jugoslaviji), što već samo po sebi govori o suprotstavljenim pozicijama ovih autora. Ako je za obojicu sam rat svojevrsni silazak u Had, onda izlazak u Cistilište i katarza nisu isti: ostajući dosledan antikomunista, Lazarević vodi svoje dnevnike sve do hapšenja (krajem četrdesetih godina 20. veka), dok Vinaver pokušava već od 1945. da se uklopi u mirnodopski establišment - pre svega onaj književni. Iz tih razlika i protivurečnosti proizilaze i raznolike intelektualne opservacije, esejističke refleksije i filozofeme koje (opet paradoksalno ili ne?) dominiraju i u Lazarevićevim (1942-1947) i u Vinaverovim (1941-1945) memoarsko-dnevničkim zapisima.

Ključne reči: Branko Lazarević, Stanislav Vinaver, memoarsko-dnevnička proza, Drugi svetski rat

( )

va korifeja dve srpske moderne, one prve koja se razvijala početkom 20. veka pod patronatom Srpskog književnog glasnika (odnosno, skrelićevsko-bogdanpopovićevske književne ideologije) i one druge, koja je uoči Drugog svetskog rata donela istinski dah modernizma, ekspresionizma i avangarde srpskoj kulturi, našli su se tokom ratnih godina na sličnim pozicijama, samo sada vanliterarnim. ${ }^{1}$ Branko Lazarević, koji je najvažnije stranice svoga opusa ispisao još u mladosti (prve dve decenije 20. veka) i Stanislav Vinaver, čija je modernistička bitka i borba za jednu novu književnu modernizaciju u doba socijalizma potrajala sve do smrti (1955), tokom Drugog svetskoga rata našli su se u svojevrsnoj „unutrašnjoj emigraciji”, sprečeni da javno deluju, ali promišljajući i dalje strastveno pitanja koja

Rad je rezultat istraživanja na projektu 178005 pod naslovom „Aspekti identiteta i njihovo oblikovanje u srpskoj književnosti” koji finansira Ministarstvo prosvete i nauke Republike Srbije (rukovodilac projekta: prof. dr Gorana Raičević). 


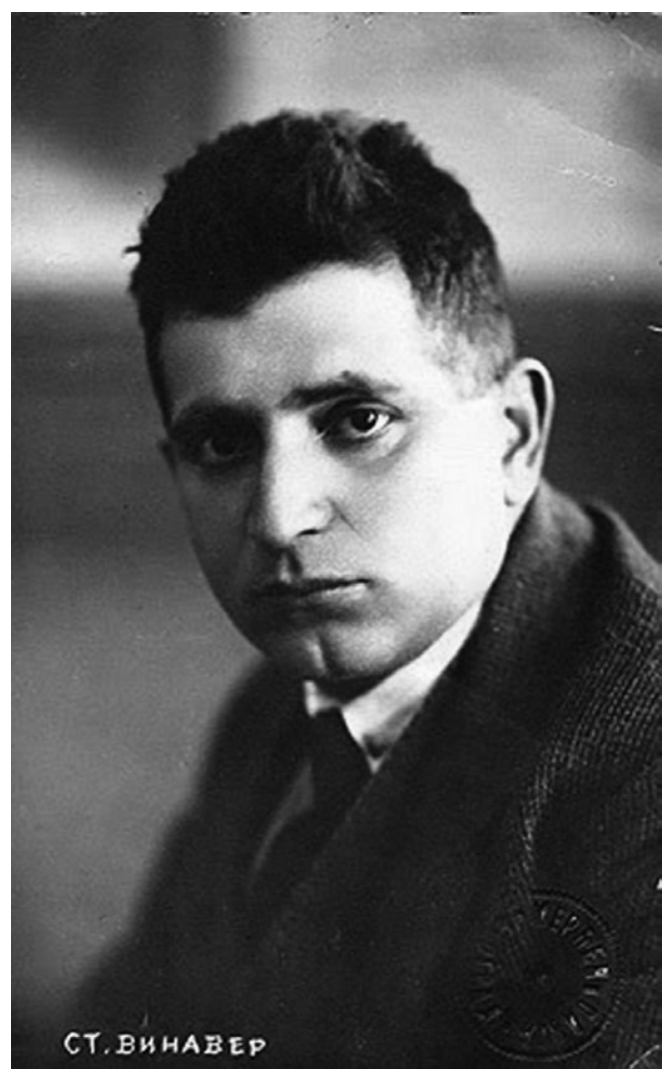

Slika 1. Stanislav Vinaver

su odredila njihove poetike, estetike, filozofije i - na kraju krajeva - same životne sudbine.

Kao rezervni oficir vojske Kraljevine Jugoslavije, Vinaver je odmah po aprilskom slomu 1941. pao u zarobljeništvo i narednih pet godina proveo je po „oflazima” nacističke Nemačke. ${ }^{2}$ Branko Lazarević, koji je u istoj toj Kraljevini bio diplomata visokoga ranga, nije prošao logorsku sudbinu ali je - delimično zaštićen i diplomatskim imunitetom (poput Iva Andrića i drugih) - ratne dane proveo u razorenom, izolovanom, opustelom, dakle u polulogorskom, tj. logoroidnom Beogradu. Uspomene Stanislava Vinavera (Godine poniženja i borbe, uz jasan podnaslov: život u nemačkim „oflazima”) imale su veliku specifičnu težinu jer su se pojavile u trenutku dok su još tinjala ratna zgarišta - rukopis je odobren za štampu 28. juna 1945 ! - a još veću ako se ima na umu (a to se u ono vreme dobro znalo!) da ih je pisao autor koji nije eksplicitno pripadao pobedničko-komunističkoj ideološkoj matrici. ${ }^{3}$ I zaista, u toj knjižici nema za ono doba očekivanog udvoričkog diskursa - kakvome neće odoleti jedan Ivo Andrić, Veljko Petrović ili Marko Ristić, na primer! Nema čak ni preterivanja u osudama i vrednovanjima uopšte, što je takođe bilo karakteristično za prve godine posleratne „obnove i izgradnje”. Vinaver je u najvećoj mogućoj meri sačuvao dostojanstvo, insistirajući na objektivno-analitičkom tonu svojih sećanja, u čemu mu je pomogla najpre sama polazna tačka posmatranje logora kao svojevrsne eksperimentalne retorte, u kojoj se jasno sagledava kvintesencija svih spoljašnjih zbivanja - a potom i izvesni univerzalizam karakterističan za njegov celokupni literarni opus, tj. pokušaj da se sve smesti u najširi istorijsko-civilizacijski kontekst. Stoga je Stanislav Vinaver mirne duše mogao - iako nije! - mnoge kategorije koje razmatra (Zlo, Patnja, Dobrota, Znanje i t.sl.) pisati simbolički, velikim slovom, jer su one vanvremene i suštinske, a pojavljuju se u datim uslovima na svoje specifične načine.

Koji su to načini obeležili nemačke „oflagere”?! Pošto je reč o vojno-zarobljeničkim (prevashodno oficirskim!) logorima, metodologija je bila potpuno drugačija nego u zloglasnim konclogorima smrti, ali ipak nimalo humana, daleko od pravila Żenevske konvencije - kako to, uostalom, najčešće i biva u samoj ratnoj praksi! Ono što Vinaver sa opravdanim zaprepašćenjem uviđa, jeste činjenica da su sami zarobljenici - sasvim zapostavljajući minimum oficirske etike, a zakletvu pogazivši već u samom aprilskom porazu 1941! - bili najsavršeniji kapoi: što višeg zvanja u nekadašnoj vojsci, to drastičniji (ili suptilniji?) u raznim

Oflager, t. j. Offizierslager, njemački logori za zarobljene oficire protivničkih vojski. (nap. ur.)

Stanislav VINAVER, Godine poniženja i borbe: život u nemačkim „oflazima”, Beograd 1945. 
parasadističkim metodama. Slična („unutrašnja”) hijerarhijska organizacija primenjivana je, doduše, i inače u logorima svih ideoloških boja tokom istorije, ali ovde je šokirala činjenica da većina logoraša - poput samoga pisca - nije pripadala profesionalnom, već rezervnom oficirskom korpusu: dakle, bili su to ljudi visokog, pa i najvišeg civilnog (često tzv. „humanističkog”) obrazovanja. I tu se, kao po nekom horor-pravilu, ogledala paradoksalna srazmera: što više obrazovanje, to niži moralni i uopšte ljudski pad. Zato će retki izuzeci od ovakvog pravila biti još briljantniji. Sam Vinaver je fizički najbrutalnije zlostavljan kao neistomišljenik jednoga eks-generala eks-kraljevske vojske i njegovog logorskog (eks-jugoslovenskog!) klana: prebijanje i iživljavanje nad njim, uz stručni veterinarsko-lekarski pokušaj škopljenja, zaustavljeno je samo zato da Nemci - kao upravnici „oflaga” u kojem se sve zbivalo - ne bi bili nezadovoljni radikalnim merama, sprovedenim bez njihove izričite zapovesti. Dakle, „svoji” su bili gori okupatori od nemačkih okupatora, koji je čak sa nevericom gledao na takvu degradaciju školovanih oficira i intelektualaca iz rezervnog sastava vojske: pripadnici Vermahta, Abvera, pa i Gestapoa smatrali su da je u pitanju neko ratno lukavstvo ili trik za nadmudrivanje neprijatelja, a ne istinsko dodvoravanje i podsvesno poistovećivanje sa identitetom moćnog Pobednika i Gospodara.

Stanislav Vinaver samo mestimice pominje konkretna imena „unutrašnjih zlostavljača”, očito svestan da u vreme kada njegova knjiga izlazi svaka konkretizacija te vrste može predstavljati ne samo obično denunciranje nego i sinopsis za realnu optužnicu pred sudovima novih, komunističkih vlasti u domovini. Zato on pred kraj knjige iskazuje izvesno razumevanje za posrnuća svojih sapatnika, tumačeći to emotivnim, fiziološkim (glad i bolest), pa i političkim (neinformisanost i dezorijentacija) razlozima koje je logorski sistem nametao. Takođe u sličnom duhu, on ne insistira previše na svojoj levičarsko-antifašističkoj orijentaciji, mada ne propušta da povremeno istakne kako je na logorskim predavanjima i diskusijama zastupao stav da su jedini autentični heroji ovoga rata kod nas - gerilski partizanski pokret, narodna vojska i njen komandant Tito: on ih sagledava kao prave nastavljače epskoherojske tradicije hajduka, uskoka pa čak i žrtvenih kultova (tipa „vidovdanskog zaveta”). Svetli primeri među njegovim logorskim drugovima uglavnom su pripadnici kulturnog i umetničkog miljea: pisci, slikari, novinari, deo univerzitetske inteligencije, koji iako nisu obučavani za ratne uslove niti je rat bio njihova profesija, uspevaju da iskažu ono najbolje u našem herojskom etosu i identitetu, bez obzira na to što su poraženi, zatočeni, utamničeni. Jasan osećaj da se dešavaju važne civilizacijske promene i da nastupa jedna nova epoha u kojoj će vrednosti koje zastupaju nacisti i starostavni nacionalisti svih boja (ne samo oni u Nemačkoj) zadugo biti anahronizam, reprezentuju pisca ovih uspomena kao čoveka uistinu spremnog na promene i inovacije, dakle - kao biće modernog senzibiliteta i u zrelim godinama. (Tada je uveliko prešao pedesetu!)

Negde u toj dihotomiji (staro-novo) ogleda se i „laboratorijska” kvintesencija eks-jugoslovenskih oficira-logoraša, pri čemu se „staro” ne doživljava kao a priori loše - ukoliko je uistinu utemeljeno u najdubljim i najboljim tradicijskim korenima našega narodnoga ili civilizacijskoga bića celokupne ljudske rase, u onome što je Jung nazivao „arhetipsko” i „kolektivno nesvesno”, ili u onome što se kasnije imenovalo kao „etnopsihologija” ili „psihogenetika”. Eruditno-intertekstualna mreža Vinaverove autobiografske proze najbolje svedoči o tome: on se rado poziva na uzorne primere iz Istorije, od Staroga sveta i Antike, preko srednjovekovlja i renesanse pa sve do novijih, pa i najnovijih vremena („uzorne” i sa pozitivnom i sa negativnim konotacijama, u zavisnosti od njegovog vrednovanja aktuelnih pojava!), a posebno mu je bliska tada moderna antropološka literatura - Frejzer, Malinovski i 
drugi - koja proučava ishodišta i primarne modele kulture. Dakle, spoljašnja ratna zbivanja ovde nemaju samo unutrašnje odjeke - „oflageri” kao svojevrsne eksperimentalne retorte, laboratorijske epruvete gde se matematički precizno kristališe i iskazuje sve! - nego u beskrajnim intelektualnim i kvaziintelektualnim debatama zatočenika čitalac prolazi i malu istoriju ideja, političke filozofije, moralno-etičkih shvatanja, pa i kreativnog znanja učesnika tih debata. Katarzični smisao svih tih zbivanja više je nego jasan, barem u Vinaverovim refleksijama, ali i u doživljajima njemu bliskih sapatnika, koji takođe aktuelno stradanje vide kao svojevrsni put iskupljenja i mogući uvod u suštinski novi život, dakle kao pravu katarzu u aristotelovskome značenju toga pojma. Paradoksalno je ali istinito: kriza identiteta manje je izražena tamo gde je primarna borba za goli život (tačnije - preživljavanje!), a to su zarobljenički logori, nego na tzv. „slobodi”, u okupiranoj zemlji - što se, s druge strane, vidi iz Lazarevićevog Dnevnika jednoga nikoga. ${ }^{4}$

Možda taj ton katarzičkog, dakle tragičkog, ali u biti ipak blago optimističkog senzibiliteta koji odlikuje Vinaverovu knjigu (a kakvog nema kod čuvenog intelektualnog i čulnog hedoniste Branka Lazarevića!), najbolje određuju naslovi njenih ključnih poglavlja - posebno dva poslednja: Kad padnu žice i Smisao logorskog eksperimenta. Deluju gotovo naučnički objektivno, bez imalo patetike ili pak najgorčeg nihilizma, koji već na prvi pogled odlikuju Dnevnik jednoga nikoga Branka Lazarevića - uostalom, već sam naslov kazuje kako je on definisao svoj identitet u okupiranom Beogradu (za njega okupiranom i nakon sloma Nemačke, u doba ustoličenja jugoslovenskog komunizma). Vinaverova katarza sadržana u (naslovnoj) sintagmi "godine poniženja i borbe" (istakao S.D.), uz podnaslov koji svedoči da je reč o životu a ne smrti u nacističkim „oflazima”, uvode jednu vrstu antičkog osećaja tragično-katarzičnog kroz ideju agona - borbe, dok jedan niko kod Lazarevića više vuče na odisejevski gubitak identiteta i beznađe u vihornim lutanjima koja traju sve dok opet ne nađe svoj dom. Gde je za Odiseja taj dom, gde za Lazarevića? Ovaj drugi, inače sjajni kritičar, Skerlićev i Popovićev najbolji učenik, vrhunski evropski esteta i potom još briljantniji kraljevski diplomata koji će životne užitke pretpostaviti samoj Književnosti, uistinu tokom nemačke okupacije gubi najbližu porodicu (ženu, sinove), dok njegov antički alter-ego to samo umišlja iako ga nada nikada ne napušta. Odsustvo nade i smisla kod Branka Lazarevića toliko je da se može meriti sa najvećim nihilistima u srpskoj i svetskoj poetskoj i filozofskoj tradiciji (od Sterije do Siorana): ${ }^{5}$ rezignacija sa kojom posmatra ljude, čak i bivše prijatelje i kolege, usred ratnih bespuća, nije tek lične prirode, ona je pre gađenje nad ljudskim bićem kao fenomenom! Za razliku od takođe velikoga erudite Vinavera, Lazarević u kompletnoj istoriji ne vidi puno nade i svetlih primera - jedino ga uspomene na lepe predratne dane kada je bezbrižno živeo (posebno na njegove brojne i neobične erotske avanture) povremeno „smekšaju" i čitalac kao da vidi blagi osmeh na licu tog neobično šarmantnog i harizmatičnog čoveka (o čemu su svedočili brojni savremenici, a Ivo Andrić mu čak u starosti zavideo na tim osobinama!).

Branko LAZAREVIĆ, Dnevnik jednoga nikoga. Deo 1 (1942-1946), Beograd 2007. ISTI, Dnevnik jednoga nikoga. Deo 2 (1947), Beograd 2007.

Upravo drugačiji senzibilitet u sopstvenoj ratnoj odiseji Stanislav Vinaver iskazuje već samom posvetom (motom) knjige Godine poniženja i borbe - citatom iz Homerove Odiseje: „Zemlja je tamo i grad Kumerana, naroda kojeg / magla obuzima i mrak..." 
Dnevnik jednoga nikoga počinje 1942. godine (a završava 1947, uoči autorovog hapšenja i robijanja), međutim čitavu dvotomnu knjigu najbolje karakteriše Uvod napisan - ne slučajno! - 9. oktobra 1944. u Beogradu, dok se menja vlast, tj. dok se Nemci povlače a sa strahom očekuje ulazak Rusa i partizana kao „oslobodilaca”. Lazarević već u prvim redovima ističe kako su entiteti „niko”, „ništa”, „nigde” i „nikada” oduvek bili „krst njegove vere” i kako su ga - čim bi se u njemu budio neki novi izvor - vraćali u večno ništavilo. U njemu je taj osećaj bio toliko snažan da je želeo navedene reči urezati u svoj letnjikovac na Hvaru, kao neku vrstu grba i večnog motoa sopstvenog života: stoga je i sam rat doživeo kao svetski haos, kao slom svih univerzalnih ideja i nada, a svoju privatnu nesreću kao logičan deo toga haosa i sna (o sreći?) koji smo sanjali milenijumima, kao „senkine senke senka”. Opet je važno istaći: kod Vinavera, uprkos neuporedivo gorim i nižim uslovima života (ne samo u egzistenci-

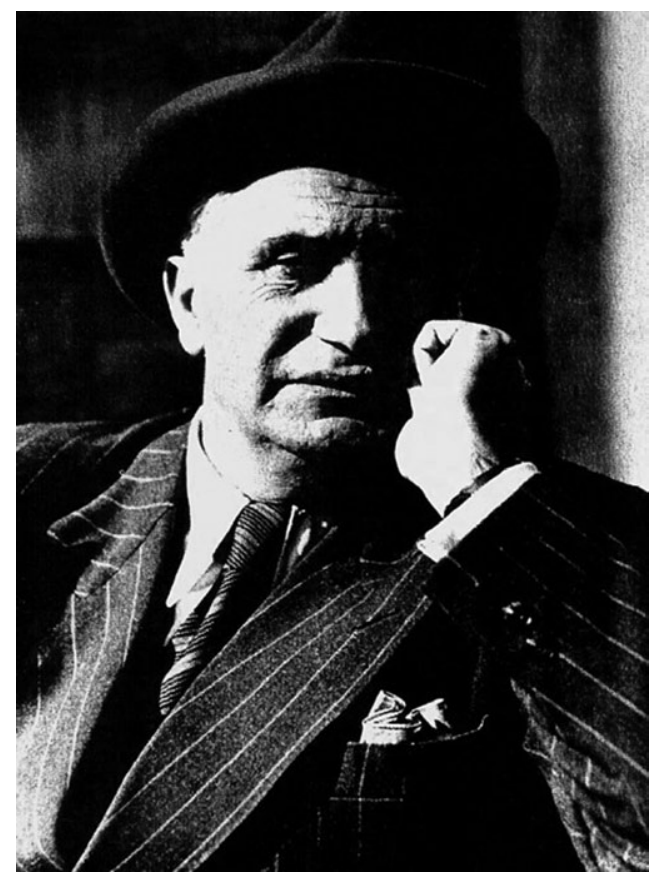

Slika 2. Branko Lazarević jalnom već i u etičkom i svakom drugom smislu) tinja nada da je daleki Dom ipak neki spas, da poniženja i borba kroz koje prolazi donose pozitivan ishod na kraju. Lazarević, iako mnogo slobodniji (u Beogradu je, a ne u „oflagu”!), eksplicira potpuno suprotan stav: celokupna egzistencija pojedinca i vrste jeste jedna žalosna borba bez pobede i ikakve nade, jedna tragična koještarija u kojoj se može postaviti hiljade pitanja zašto, ali da istinski odgovori ne postoje! Zašto je to tako upravo za Vas, gospodine Lazareviću - može se pitati svaki čitalac, pa i pisac ovoga ogleda: zašto ste višedecenijski aktivizam, optimizam i hedonizam tako lako slomili o hridi jedne patnje koja nije unikatna u istoriji Sveta, čak se može reći da je i u ovdašnjoj maloj istoriji već hiljadu puta viđena?! Da li su onda vaši sunarodnici trebali u prethodnom velikom svetskom ratu, kada su preživljavali nezapamćenu kolektivnu Golgotu, svi kolektivno da izvrše samoubistvo, a ne da se krepe na južnim morima (ponajviše grčkom) i spremaju za odlučujuću, pobedničku bitku: zašto ste, konačno, i Vi sami, tada preuzeli zapaženu ulogu u kulturnom životu emigrantskom - dakle ne u Vašoj prestonici, nego na dalekom Krfu, gde ste sa uspehom uređivali čuveni i za južnoslovenske književnosti prevažni Zabavnik?!

Zašto se ipak ratni, okupirani Beograd kod Lazarevića pokazuje manje strašnom tamnicom od onog oslobođenog (1944) i od celokupne jugoslovenske nove slobode koja nakon rata nastupa? Razlozi tu nisu samo u privatnim, porodičnim tragedijama koje je preživeo ili u političkom neistomišljeništvu sa novom vlašću (zbog čega će i robijati), nego prevshodno u njegovom suptilnom etičkom i društvenom senzibilitetu, koji doba „obnove i izgradnje” vidi kao još veće licemerje, laž i poraz ljudskosti od onih koje je promovisala nacistička ratna mašinerija: nju - paradoksalno jer je antifašista! - ni ne vidi suštinski nemoralnom i fingiranom, nego pakleno destruktivnom i otvoreno nehumanom u samim premisama i celokupnoj praksi. Dakle, Zlo po sebi manji je problem od zla koje se lažno predstavlja 
kao Dobro, i tu bi se možda mogao povući tanki zajednički imenitelj između njegovog i Vinaverovog poimanja stvari, mada Vinaver u svojim uspomenama nije ostavio eksplicitna svedočanstva o toj poratnoj „novoj eri” - možda i zato što je san koji je sanjao zatočen u dalekim „oflazima” bio jači od potonjih stvarnosnih uvida? Jer, istorija nam svedoči da ni autor Godina poniženja i borbe nije bio bezrezervno prihvaćen u komunističkoj vlasti, u najmanju ruku - imao je nemerljivo niži kulturni i literarni status od onog koji mu je realno pripadao, iako mu nikada nisu bila oduzeta građanska prava i nije poput Lazarevića robijao. Očito, intelektualne mrvice bile su presudne i dovoljne najbriljantnijim umovima u poratnom kontekstu, o čemu dramatično svedoči i nekoliko marginalnih beležaka o Vinaveru u Lazarevićevom dnevniku. $U$ tom smislu, deluje gotovo neverovatno da je izvesnu zavist, pa i uzdržanost, prema Stanislavu Vinaveru Branko Lazarević pokazivao zbog mnogo sitnijeg „lova u mutnom” od onoga koji bi se s pravom mogao pripisati jednom Andriću ili nekim drugim istaknutim intelektualcima (recimo, filologu Aleksandru Beliću, predratnom, ratnom i poratnom predsedniku SANU!): gledajući ga kako se - doduše „na kašičicu”! - uključuje u javni kulturni život, Lazarević čak izriče sumnju da je Vinaver doušnik ideoloških komesara u novom književnom establišmentu! Dakle, sama činjenica prisustva na javnoj sceni u komunističko doba za njega je izdaja temeljnih intelektualnoetičkih i moralnih načela!

Upravo u ovom paradoksu treba sagledati i srž problema: naime „strategija eskapizma” koju su tokom rata i okupacije negovali mnogi intelektualci u Beogradu, za Branka Lazarevića nije izgubila aktuelnost ni posle oslobođenja od Nemaca, jer mu se činilo da u samoj metodologiji uvlačenja intelektualaca u sistem (tačnije: u metodologiji veoma raznovrsnih, perfidnih ucena!) nema bitne razlike između „oslobodilaca” i „okupatora”. Da li je bio u pravu, da li je sledeći takav glas svoje savesti platio previsoku cenu: ne samo robijanjem u poznim godinama nego i prinudno-dobrovoljnom marginalizacijom svoga ogromnog znanja i kreativnoga dara?! Ako bismo za odgovor pitali Stanislava Vinavera, morali bismo pre svega da imamo na umu činjenicu da on čak ni u zatočeništvu „oflaga” nije sasvim prihvatao „strategiju eskapizma” već je organizovao javna i tajna predavanja, pozorišne predstave, neku vrstu kulturnog i duhovnog života čak i u takvim uslovima: očito, modernističkoavangardni duh pobune i aktivizma nije ga napuštao do kraja života, bez obzira na načine kako ga je u kom periodu (i kontekstu!) mogao ispoljavati. Isto tako, za taj odgovor bilo bi važno i saznanje da je njegov intelektualni elitizam bio drugačije vrste no Lazarevićev, koji je - ne samo zbog višedecenijske visoke diplomatske karijere! - podrazumevao i izrazitu sociološku dimenziju (kobnu za njega u „posleratnom ratu i okupaciji” nove, komunističke vlasti): ta dimenzija, iskazivala se pre svega kroz prezir i gađenje prema svakom populizmu u kome je video samo bahatost, primitivizam, sebičnost i glupost, čak toliko da je - iako racionalnog duha - bio bliži iracionalnoj, u biti nerealnoj slici stvarnosti. ${ }^{7} S$ druge strane, Stanislav Vinaver - iako mnogo iracionalniji duh! - permanentno pokušava da prevaziđe tu „iracionalnu sliku stvarnosti” (čak i u logorskim uslovima, nalazeći alternativne kanale informacija!), a na populizam i uopšte pokrete masa gleda kao na nužnost svakog istorijski prelomnog trenutka, nužnost iznad i izvan koje su najviši intelektualni, etički i estetički

Nataša MILIĆEVIĆ - Dušan NIKODIJEVIĆ, Svakodnevni život pod okupacijom (1941-1944), Beograd 2011.

„Iracionalna slika stvarnosti” kao strategija prevazilaženja komunikacijskih prepreka koje nameće cenzura u totalitarnim društvima ili vanrednim okolnostima (kakve su rat, zatvori, logori...), često je - ali ne i obavezno! - u opreci sa realnošću samom (vidi belešku 6). 
kriterijumi: pojednostavljeno govoreći, takav stav podrazumeva da su Umetnost i duhovnost uopšte, same po sebi vredne svake žrtve i raznih (ali ne baš svih) kompromisa u realnosti!

To i jeste, na kraju krajeva, najveći paradoks: beskompromisni polemičar i poetički veoma radikalni Vinaver spreman je u ratu (kao i nakon njega!) na svojevrstan „pakt sa stvarnošću” zarad viših ciljeva, dok poetički i filozofski umereniji Branko Lazarević u ime tih istih ciljeva vodi rat sa stvarnošću čak i posle okončanja konkretnog globalnog vojnog konflikta, Drugog svetskog rata. Intelektualac kao večno misleće biće svakako ne može zanemariti ni onaj ne-refleksivni, najsiroviji deo Stvarnosti (kako ratne, tako i mirnodopske). Pitanje kriterijuma koji se prelamaju između teorije i prakse, apstraktnog i elementarno konkretnog, između virtuelnog i egzistencijalno-realnog, ukazuje se na primeru Vinaverovih i Lazarevićevih književnih svedočanstava više nego dramatično, dramatičnije u razlikama između njih nego u istovetnostima: ove druge, bez imalo sarkazma, mogao bih podvesti pod „opšta mesta” u doživljaju rata svakoga iole inteligentnijeg, savesnijeg i moralnijeg čoveka, u svakom ratu i svakoj eposi. Ono što za sve nas, danas i ovde, ostaje kao najbitnije pitanje jeste da li smo u ratovima i poratnim slobodama (ili „slobodama”) koje smo mi lično iskusili bili bliže vinaverovskoj ili lazarevićevskoj paradigmi, tačnije - da li se kajemo što u tom kontekstu nismo bili drugačiji ili bismo i sutra ponovili isto?! Ne opredeljujući se ni za jednu od dve pomenute paradigme - ne samo zato što uistinu postoje i one treće, četvrte ili pete (ne znam koliko, ali svakako više od dve!), nego i zato što je sa distance od 70 godina besmisleno vrednovati išta osim vrednosti samih tekstova Stanislava Vinavera i Branka Lazarevića - ja svoj privatni odgovor na prethodno pitanje znam i uvek ga iznosim javno: baš zato mi nikada nije ni padalo na pamet da se tom jezovitom i tragičnom tematikom ozbiljnije literarno pozabavim, u fikcionalnom ili nefikcionalnom vidu, svejedno. Ali, to može biti tema jednoga budućeg teksta čija provenijencija, suština i ciljevi - po mome najdubljem uverenju - nikako ne mogu posedovati prevashodno estetički (pa čak ni estetičko-filozofski) identitet, makar se lažno predstavljali takvima...

C.9

\section{BETWEEN WARTIME BELGRADE AND THE LABOUR CAMPS OF Germany: Branko Lazarević and Stanislay Vinaver}

Two prominent figures of Serbian Modernism, Branko Lazarević (1883-1968) and Stanislav Vinaver (1891-1955) found themselves in different circumstances of personal nonfreedom during the Second World War. While Lazarević, as a renowned diplomat of the former state, managed to reach Belgrade and spend the occupation there, Vinaver spent the entire war in the concentration camps of the Third Reich. Their memories of those years testify to the same cataclysmic and cathartic experience of wartime chaos, as well as to the distinctively diverse perspectives regarding numerous ethical, cultural and even political issues. Dnevnik jednog nikoga (The Diary of a Nobody) by Branko Lazarević was to be published as late as 2008 (posthumously), while Godine poniženja i borbe (The Years of Humiliation and Struggle) by Stanislav Vinaver was published in 1945 (in a newly liberated Yugoslavia), which is in itself indicative of the opposed viewpoints of the two authors. For the former, the defeat of Germany and its allies did not mean the end of the war, on 
the contrary - for him, the war continues even as the new, communist government is being established. For the latter, leaving the concentration camps represents entering the realm of freedom, regardless of the circumstances which await in his homeland. If, for both of them, the war meant descending into Hades, the act of ascending into the Purgatory and catharsis are nevertheless not the same: remaining consistent in his anti-communist attituteds, Lazarević kept his diaries until his arrest (in late 1940s), while Vinaver sought to fit in with the peacetime establishment, above all the literary one, as early as 1945 . That is why wartime Belgrade, paradoxically or not, emerges in these precious and unusual books as more of a small dungeon than the postwar Yugoslav reality, (as an abstract, yet desired beacon of freedom) the subject of dreams of an individual imprisoned in German "labour" camps. Out of those differences and discrepancies there emerge diverse intellectual observations, essayistic reflections and philosophemes which (again, paradoxically or not) dominate both, Lazarević's (1942-1947) and Vinaver's (1941-1945) memoirs and diaries.

Keywords: Branko Lazarević, Stanislav Vinaver, memoirs and diaries, World War II

\section{$\cos$}

\section{Literatura}

Branko LAZAREVIĆ, Dnevnik jednoga nikoga. Deo 1 (1942-1946), Beograd 2007.

Branko LAZAREVIĆ, Dnevnik jednoga nikoga. Deo 2 (1947), Beograd 2007.

Nataša MILIĆEVIĆ - Dušan NIKODIJEVIĆ, Svakodnevni život pod okupacijom (1941-1944), Beograd 2011.

Stanislav VINAVER, Godine poniženja i borbe: život u nemačkim „oflazima”, Beograd 1945. 